\title{
Comparative breeding performances of indigenous climbing perch (Anabas testudineus) populations in a newly developed semi-artificial condition
}

\author{
MOHAMMAD SHAFIQUL ALAM*, NAYAN CHANDRA MONDAL, \\ KANIZ FATEMA ${ }^{1}$, NARGIS SULTANA ${ }^{2}$ AND MD. JAHANGIR ALAM ${ }^{2}$ \\ Department of Genetics \& Fish Breeding, \\ Bangabandhu Sheikh Mujibur Rahman Agricultural University (BSMRAU), Gazipur, Bangladesh \\ ${ }^{1}$ Dept. of Fisheries \& Marine Bioscience, Jashore University of Science \& Technology \\ Jashore, Bangladesh \\ ${ }^{2}$ Department of Fisheries Biology and Aquatic Environment, BSMRAU, Gazipur \\ *Corresponding Author: msalambd@bsmrau.edu.bd
}

\begin{abstract}
The indigenous Anabas testudineus populations from two different regions were bred in a newly developed semi-artificial breeding condition in modified 500L plastic tanks, with inlet and outlet systems having continuous water supply facilities. The induced breeding was performed through synthetic hormone "Flash" and a single dose was used as $0.2 \mathrm{ml} / \mathrm{kg}$ for females and $0.1 \mathrm{ml} / \mathrm{kg}$ for male fishes. The experiment was set with four treatments such as $\mathrm{T}_{1}$ Purebred: (Netrokona $\$ \times$ Netrokona $\sigma^{\gamma}$ ), $\mathrm{T}_{2}$ Purebred: (Sylhet $q \times$ Sylhet $\sigma^{7}$ ), T 3 Crossbred (Sylhet $q \times$ Netrokona $\sigma^{7}$ ), and T 4 Crossbred (Netrokona $q \times$ Sylhet $\sigma^{\prime}$ ) with three replications each. The ovulation rate was higher in $\mathrm{T}_{3}$ for the Sylhet female population (445.358 \pm 14.18/gram body weight). The fecundity of Sylhet female ( $\mathrm{T}_{2}$ and $\mathrm{T}_{3}$ ) was $24000-30000$, and the fecundity of Netrokona female ( $T_{1}$ and $\left.T_{4}\right)$ was 15000-20000. The highest and lowest fecundity was found in $T_{3}$ $(29444 \pm 1988)$ and $T_{1}(16888 \pm 346)$, respectively. The highest fertilization rate was recorded $(90.41 \pm 2.10 \%)$ in $\mathrm{T}_{2}$ and $(89.46 \pm 41.50 \%) \mathrm{T}_{4}$, while the lowest fertilization rate was $84.58 \pm 2.40 \%$ in $\mathrm{T}_{3}$. The highest hatching rate was $77.16 \pm 2.33 \%$ in $\mathrm{T}_{2}$, and the lowest hatching rate was $42.23 \pm 1.58 \%$ in $\mathrm{T}_{3}$. Also, a higher survival rate was found in $\mathrm{T}_{2}$. The present study indicated that the breeding performances were better in the Sylhet population than the Netrokona population in the developed semi-artificial condition.

Keywords: Anabas testudineus, Induced breeding, Plastic tank incubator,
\end{abstract}

\section{Introduction}

The climbing perch, Anabas testudineus (Bloch, 1792) of the family Anabantidae, is popularly known as "koi" in Bangladesh is a small-sized food fish inhabiting both freshwater and brackishwater in the most tropical or subtropical areas (IUCN 2015, Talwar and Jhingran 1991). Among SIS (small indigenous species), A. testudineus has been considered as one of the potential candidates for aquaculture and captive breeding (Ponniah and Sarkar 2000). Once upon a time, indigenous climbing perch was very much abundant in almost all freshwater systems of Bangladesh (Mahmood 2003) but its availability has been declined in recent years. Sarkar et al. (2005) and Bhattacharyya and Homechaudhuri (2009) optimized induced breeding technique of this species using different doses of a synthetic hormone, Wova-FH, and Ovaprim, respectively. Seed production technology of $A$. testudineus through artificial propagation was developed in captive conditions (Kohinoor 1991, 2008), but the growth rate of native strain is very slow in the pond's ecosystem.

https://doi.org/10.52168/bjf.2021.33.03 
In 2002, a fast growing strain of $A$. testudineus known as Thai koi was introduced in Bangladesh for culture purposes. Due to the failure of maintaining a proper hatchery protocol in the fry production phase, inbreeding has resulted in reducing the high yielding characteristics of Thai koi (Kohinoor and Zaher 2006). To overcome this situation, Sharnalata Agro Fisheries Limited introduced another very fast growing Vietnam koi in Bangladesh in 2010, for its higher production and growth than the other variety of climbing perch (Shafiquzzoha et al. 2018, Hafijunnahar et al. 2016). It was observed that Vietnam koi grows as much as $250-300 \mathrm{~g}$ within 120 days of culture period, and the body color is almost similar to native koi (Amin et al., 2015). Nevertheless, consumers do not widely accept this fish due to lack of taste and natural odour compared to native koi. Consequently, induced breeding of indigenous climbing perch needs to be prioritized, and breeding technique needs to be improved.

One of the major constraints in breeding this species is the collection of quality brood fish from nature without any stock information. In the previous experiment (Alam et al., unpublished data), quality brood fish of native koi was identified, and broodstock was developed for seed production. The population from Netrokona and Sylhet in Bangladesh was considered good broodfish for breeding performances. Thus, this study aimed to study comparative breeding performances of two different populations of Bangladeshi $A$. testudineus and develop a semiartificial breeding technique for captive conditions.

\section{Materials and Methods}

Broodfish rearing and breeding facilities development: Broodfish rearing and breeding facilities were developed before starting the experiment, besides the faculty building of Bangabandhu Sheikh Mujibur Rahman Agricultural University, Gazipur. The mini hatchery has six cemented cisterns $\left(5^{\prime} \times 3^{\prime} \times 4^{\prime}\right)$ for brood fish rearing, two $\left(6^{\prime} \times 5^{\prime} \times 3^{\prime}\right)$ cisterns with bottom mud for hatchling rearing of indigenous climbing perch. A plastic tank $(500 \mathrm{~L})$ was used for supplying water holding in the rooftop in a house was used as an incubator for spawning and hatching fish after modification. The upper side of the tank (6 inches) was cut and removed, and it was then open on the upper side. Inside the tank outlet, a short piece of pipe (with a diameter of 0.5 -inches and a length of 15 inches) was horizontally set and came to the center of the tank and then using another short piece of pipe (15 inches) used vertically with the elbow. The outside outlet of the tank was also connected with another short piece of pipe having a height of 15 inches. Thus, the water level was maintained by lowering both the inside and outside vertical pipe upward and downward. The mouth of the inlet and outlet pipe was covered by a fine mesh size net so that the egg cannot come outside of the tank along with the water flow. The upper opening mouth side of the tank was also covered by a fine mesh size net so that fish can't escape from the tank. The tank was then set under a horizontal water supply system by a short porous piece of pipe (36 inches) with the dead-end mouth. Thus, twelve plastic tanks were prepared and used for breeding in the present experiment. Digital electric balance was used for measuring fish weight. A plastic bowl, petri dish, and beaker were used to count the number of eggs, fertilization, and hatchling.

Brood fish collection and rearing: Five hundred brood fish of native koi from each of the two populations Netrokona (Bandha beel, Mohonganj) and Sylhet (Murier haor, Golapganj) were collected in January 2017, and the fish were reared and kept in the cemented tank $\left(5^{\prime} \times 3^{\prime} \times\right.$ 
4'), having a water height of around 3 feet. Approximately 120-150 fish were kept in each cemented tank, and the fishes were fed with a commercially available feed twice daily at $5 \%$ body weight. The broodfish were fed a VitE supplement with the feed. The excess amount of feed and excreta was cleaned every day, and the whole water of the tank was changed twice a week.

Experimental design: The experiment was designed with four treatments $T_{1}, T_{2}, T_{3}$, and $T_{4}$ (treatments $\mathrm{T}_{1}$ - Netrokona $q \times$ Netrokona $\sigma^{*}, \mathrm{~T}_{2}$-Sylhet $q \times$ Sylhet $\sigma^{\prime \prime}, \mathrm{T}_{3}$-Sylhet $q \times$ Netrokona $\sigma^{\prime \prime}, \mathrm{T}_{4}$-Netrokona $\$ \times$ Sylhet $\sigma^{\prime}$ ) for two populations, and each treatment has three replications $\left(R_{1}, R_{2}\right.$, and $\left.R_{3}\right)$. Temperature and dissolved oxygen were recorded a similar $(p>0.05)$ in all treatments throughout the research period. The average temperature and dissolved oxygen with standard deviation (SD) was $28.8 \pm 05$ and $5.4 \pm 0.3,29.3 \pm 05$ and $5.1 \pm 0.3,30.1 \pm 05$ and $5.2 \pm 0.3$, and $30.2 .8 \pm 05$ and $5.4 \pm 0.3$, in $\mathrm{T}_{1}, \mathrm{~T}_{2}, \mathrm{~T}_{3}$, and $\mathrm{T}_{4}$, respectively.

Broodfish response in captivity and breeding trial: Broodfish maturity was checked weekly since March 2017 to observe whether eggs and sperm come out (Fig. 1) after gentle pressure in the abdomen. Thus, the maturity check continued, and the first maturity response was found in the first week of April. One breeding trial, including broodfish selection, hormone injection, ovulation, incubation, fertilization, hatching, all steps took around two weeks. Thus, six breeding trials were done from April to June. The breeding response was found the best in the middle of this period. However, the best three breeding trials were used in the present experiment (Table I). The male and female fish weights varied from $27-51 \mathrm{~g}$ and $37-95 \mathrm{~g}$. The average weight $(\mathrm{g})$ of brood fishes used in different trails is given in Table I. In each treatment, three pairs of male and female fishes were used, and thus, in each trial, 72 fish were used in the four treatments $\left(\mathrm{T}_{1}, \mathrm{~T}_{2}, \mathrm{~T}_{3}\right.$, and $\left.\mathrm{T}_{4}\right)$.
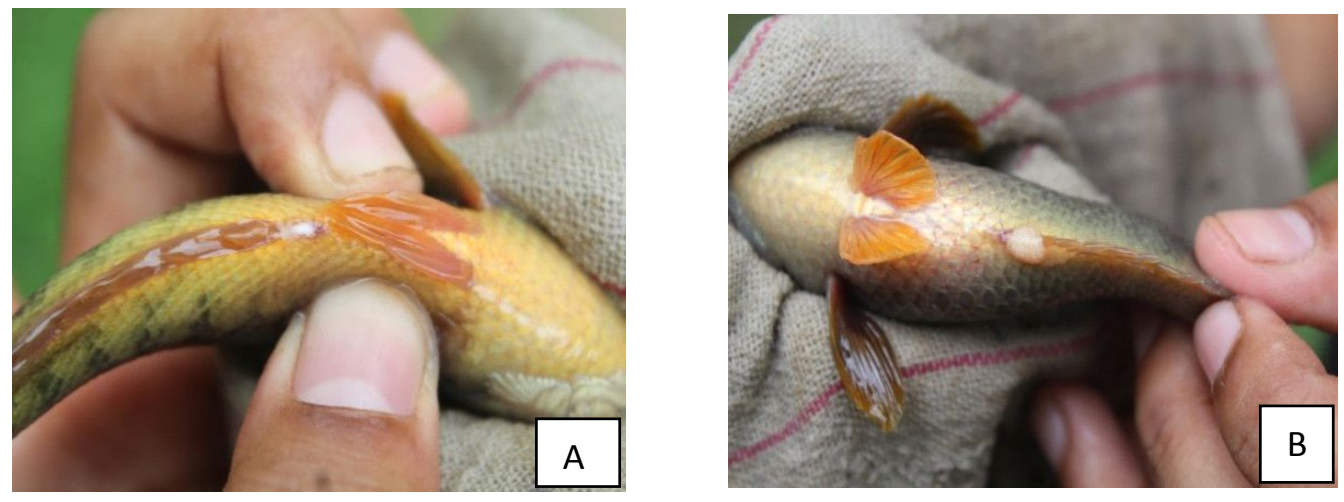

Fig. 1. Milt and eggs come out upon gentle pressure on the abdomen of male (A) and female (B) koi. 
BREEDING PERFORMANCES OF A. TESTUDINEUS IN A MODIFIED CONDITION

Table I. Average weight (g) of brood fish koi, A. testudineus used in different trails $(\mathrm{N}=216)$

\begin{tabular}{|c|c|c|c|c|c|}
\hline Date & Weight $(\mathrm{g})$ & $\mathrm{T}_{1}$ & $\mathrm{~T}_{2}$ & $\mathrm{~T}_{3}$ & $\mathrm{~T}_{4}$ \\
\hline \multirow{2}{*}{$27-04-17$} & Male & 41.0 & 38.0 & 37.6 & 41.6 \\
\hline & Female & 70.5 & 63.0 & 73.4 & 50.3 \\
\hline \multirow{2}{*}{$16-05-17$} & Male & 49.6 & 36.2 & 36.6 & 35.6 \\
\hline & Female & 80.0 & 54.0 & 62.6 & 49.8 \\
\hline \multirow{2}{*}{ 07-06-17 } & Male & 38.0 & 34.5 & 39.0 & 40.0 \\
\hline & Female & 64.4 & 51.3 & 62.6 & 62.6 \\
\hline \multirow{2}{*}{$\begin{array}{l}\text { Mean body } \\
\text { weight ( } \pm \\
\text { SD) }\end{array}$} & Male & $42.87 \pm 6.02$ & $36.23 \pm 1.75$ & $37.73 \pm 1.20$ & $39.07 \pm 3.10$ \\
\hline & Female & $71.62 \pm 17.01$ & $56.08 \pm 12.31$ & $66.22 \pm 10.38$ & $54.22 \pm 10.59$ \\
\hline $\begin{array}{l}\text { Mean } \\
\text { fecundity } \\
(+ \text { SD })\end{array}$ & & $16888.67 \pm 346^{b}$ & $24291.67 \pm 355^{\mathrm{a}}$ & $29444 \pm 199^{a}$ & $18555 \pm 376^{b}$ \\
\hline $\begin{array}{l}\text { Ovulation rate } \\
\text { (No. of egg } \\
\text { released/g of } \\
\text { fish) }\end{array}$ & & $238.54 \pm 31.07^{\mathrm{c}}$ & $431.00 \pm 16.81^{\mathrm{a}}$ & $445.36 \pm 14.18^{\mathrm{a}}$ & $344.44 \pm 80.63^{b}$ \\
\hline
\end{tabular}

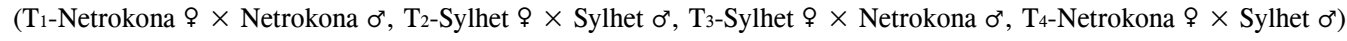
Different superscripts in the same column indicate significant differences among different treatments $(\mathrm{p}<0.05)$; One-way ANOVA followed by LSD multiple range test.

Inducing agent and injecting the broods: The broodfish were selected by observing external morphology. Synthetic commercial hormone Flash (Synthetic Gonadotropin Releasing Hormone Analogue, SGnRH, $10 \mathrm{ml}$ vial) was used. Each $10 \mathrm{ml}$ hormone contains analogue $0.002 \%$, Domperidone $0.998 \%$, Propylene glycol $99 \%$. The single dose was used as $0.2 \mathrm{ml} / \mathrm{kg}$ for females and $0.1 \mathrm{ml} / \mathrm{kg}$ for male fishes. At first, female fishes were selected and weighed by the electric balance (Fig. 2A), and kept in a plastic bucket for a short time; and at the same time, male fishes were selected and kept in a separate plastic bucket before hormone injection. The intramuscular injection of hormone was administered at the base of the pectoral fin gently (Fig. 2A).
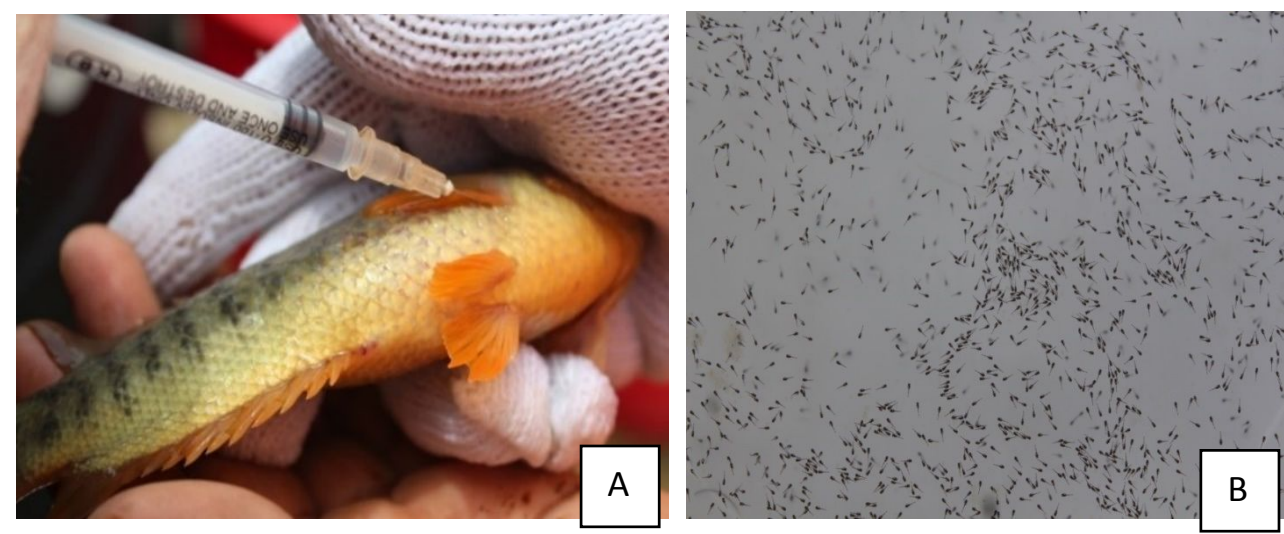

Fig. 2. Hormone injection to A. testudineus (A) and newly hatched larvae (B). 
Hatching and rearing: Eggs and milt were released from the injected fish naturally, and fertilization occurred in the tank. It was taken around 24 to 30 hours for incubation and hatching of fertilized eggs (Fig. 2B). The hatchlings did not take food from outside until the absorption of their yolk sac, and it took around three days to start feeding on the outside as the first feed. The hard-boiled chicken egg was given as the first feed for around three days. The hard-boiled yellow part of the egg was smashed with water and sieved by fine microjorjet cloth and supplied at the rate of one egg/ 20 tank and twice daily. After 5-6 days of hatching, commercially available nursery feed (Mega nursery powder feed) containing $40 \%$ protein was given in each tank. The dead hatchlings were removed carefully from the tank, and a continuous water supply was maintained; and thus, fish spawns were reared in the tank for about two weeks. Uneaten particles and dirty materials were removed periodically, and the bottom was cleaned by siphoning. After 14 days, the fry was transferred into the bottom mud cemented tank $\left(6^{\prime} \times 5^{\prime}\right.$ $\left.\times 3^{\prime}\right)$ and reared for one month.

Assessment of breeding parameters of A. testudineus: The total number of eggs and the number of fertilized eggs were calculated by the volumetric method after ovulation and fertilization in the 500L tank. At first, water containing fertilized eggs from 500L tank were taken in a 1 Liter biker and counted total eggs and fertilized eggs and recorded. This way, it counted ten times, and the average number was multiplied with the total volume of the water (average 50L) in the tank, and approximate total egg number and fertilized egg were estimated. However, fertilized eggs were transparent, while unfertilized eggs were opaque in appearance. The fertilization rate was determined by the following formula:

Fertilization rate $(\%)=\frac{\text { No. of fertilized eggs }}{\text { Total no. eggs (fertilized and unfertilized) }} \times 100$

The hatched number was counted in the same way mentioned above, and the hatching rate was determined by the following formula:

Hatching rate $(\%)=\frac{\text { No. of eggs hatched }}{\text { Total no. of eggs }} \times 100$

The survival number of spawns was recorded after 4, 7, 14 days after hatching following the method described above, and the survival rate was determined by the following formula:

No. of survived

Survival rate $(\%)=\frac{\text { Total no. of eggs }}{100}$

Statistical analysis: The gathered data were summarized and scrutinized consciously before actual tabulation. After data entry, the data were analyzed by Statistics 10.0, and the results found in the experiment were subjected to statistical analysis, ANOVA (one way), that showed the significance $(p<0.05)$ level of differences between treatments. Significant results $(p<0.05)$ were further tested by the LSD multiple range test.

\section{Results}

Fecundity and ovulation: Fecundity is one of the important factors of the biology and population dynamics of fish. In the study, induced breeding was achieved successfully in all four 
BREEDING PERFORMANCES OF A. TESTUDINEUS IN A MODIFIED CONDITION

treatments and, the latency and incubation period was 8-12 and 24-30 hrs, respectively. The highest number of the egg was found in $\mathrm{T}_{3}$, and the lowest was found in $\mathrm{T}_{1}$. In the present study, fecundity varied from 15000-30000. The fecundity was always found higher in Sylhet females. The mean fecundity of Sylhet females was 24000-30000 in treatment $\mathrm{T}_{2}$ and $\mathrm{T}_{3}$. On the other hand, the mean fecundity of Netrokona females is 15000-20000 in treatment $\mathrm{T}_{1}$ and $\mathrm{T}_{4}$. Also, the ovulation rate was higher in $\mathrm{T}_{3}(445.358 \pm 14.182)$ compared to ovulation rates found in $\mathrm{T}_{1}$ (238.54 \pm 31.07$), \mathrm{T}_{2}(431.00 \pm 16.81)$, and $\mathrm{T}_{4}(344.44 \pm 80.63)$, respectively (Table II).

Table II. Showing details of induced breeding performances of koi $\boldsymbol{A}$. testudineus

\begin{tabular}{l|c|c|c|c|c}
\hline Treatment & $\begin{array}{c}\text { Fertilization } \\
\text { rate }(\%) \\
( \pm \mathrm{SE})\end{array}$ & $\begin{array}{c}\text { Hatching rate- } \\
\text { Day 1 }(\%) \\
( \pm \mathrm{SE})\end{array}$ & $\begin{array}{c}\text { Day 4 }(\%) \\
( \pm \mathrm{SE})\end{array}$ & $\begin{array}{c}\text { Day 7 }(\%) \\
( \pm \mathrm{SE})\end{array}$ & $\begin{array}{c}\text { Day 14 }(\%) \\
( \pm \mathrm{SE})\end{array}$ \\
\hline $\mathrm{T}_{1}$ & $88.07 \pm 1.48^{\mathrm{a}}$ & $56.25 \pm 0.19^{\mathrm{b}}$ & $23.03 \pm 0.86^{\mathrm{b}}$ & $14.75 \pm 0.31^{\mathrm{c}}$ & $9.32 \pm 0.31^{\mathrm{b}}$ \\
\hline $\mathrm{T}_{2}$ & $90.41 \pm 2.10^{\mathrm{a}}$ & $77.16 \pm 2.33^{\mathrm{a}}$ & $32.79 \pm 0.90^{\mathrm{a}}$ & $22.57 \pm 0.67^{\mathrm{a}}$ & $11.9 \pm 0.45^{\mathrm{a}}$ \\
\hline $\mathrm{T}_{3}$ & $84.58 \pm 2.41^{\mathrm{b}}$ & $42.23 \pm 1.58^{\mathrm{c}}$ & $21.66 \pm 1.01^{\mathrm{b}}$ & $13.50 \pm 0.43^{\mathrm{c}}$ & $7.19 \pm 0.34^{\mathrm{c}}$ \\
\hline $\mathrm{T}_{4}$ & $89.47 \pm 1.51^{\mathrm{a}}$ & $58.34 \pm 3.97^{\mathrm{b}}$ & $31.95 \pm 0.62^{\mathrm{a}}$ & $19.49 \pm 1.23^{\mathrm{b}}$ & $\begin{array}{c}11.68 \pm \\
1.05^{\mathrm{a}}\end{array}$ \\
\hline
\end{tabular}

$\left(\mathrm{T}_{1}\right.$-Netrokona $q \times$ Netrokona $\sigma^{x}, \mathrm{~T}_{2}$-Sylhet $q \times$ Sylhet $\sigma^{x}, \mathrm{~T}_{3}$-Sylhet $\% \times$ Netrokona $\sigma^{\star}, \mathrm{T}_{4}$-Netrokona $\% \times$ Sylhet $\left.\sigma^{\prime}\right)$ Different superscripts in the same column indicate significant differences among different treatments $(p<0.05)$; One-way ANOVA followed by LSD multiple range test.

Fertilization and hatching rate: From the experiment, the fertilization rate was recorded as $88.00 \pm 1.49 \%, 90.41 \pm 2.10 \%, 84.58 \pm 2.41 \%$, and $89.47 \pm 1.51 \%$ in the treatments of $\mathrm{T}_{1}, \mathrm{~T}_{2}$, $\mathrm{T}_{3}$, and $\mathrm{T}_{4}$, respectively (Table II). The highest fertilization rate, $90.41 \pm 2.10 \%$, was recorded in $\mathrm{T}_{2}$, whereas the lowest fertilization rate, $84.58 \pm 2.41 \%$, was found in $\mathrm{T}_{3}$. The hatching rate was found $56.25 \pm 0.19 \%, 77.16 \pm 2.33 \%, 42.23 \pm 1.58 \%$, and $58.34 \pm 3.97 \%$ in treatments of $\mathrm{T}_{1}$, $\mathrm{T}_{2}, \mathrm{~T}_{3}$, and $\mathrm{T}_{4}$, respectively (Table II). The highest hatching rate was recorded $(77.16 \pm 2.33 \%)$ in $\mathrm{T}_{2}$, and the lowest hatching rate was recorded $(42.23 \pm 1.584 \%)$ in treatment $\mathrm{T}_{3}$ (Table II).

Survival rate: The survival rate of koi larvae in four different treatments (Table II) were $23.03 \pm 0.86 \%, 32.79 \pm 0.90 \%, 21.66 \pm 1.012 \%$, and $31.95 \pm 0.62 \%$ in $\mathrm{T}_{1}, \mathrm{~T}_{2}, \mathrm{~T}_{3}$, and $\mathrm{T}_{4}$, respectively after four days of hatching. The number of koi larvae gradually decreased after seven days in all treatments. The survival rate of seven-day-old koi larvae was $14.75 \pm 0.31 \%$, $22.57 \pm 0.67 \%, 13.50 \pm 0.43 \%$, and $19.49 \pm 1.23 \%$ in $\mathrm{T}_{1}, \mathrm{~T}_{2}, \mathrm{~T}_{3}$, and $\mathrm{T}_{4}$, respectively. After 14 days of hatching, the survival rate was $9.32 \pm 0.31 \%, 11.9 \pm 0.45 \%, 7.19 \pm 0.34 \%$, and $11.68 \pm 1.05 \%$ in $\mathrm{T}_{1}, \mathrm{~T}_{2}, \mathrm{~T}_{3}$, and $\mathrm{T}_{4}$, respectively (Table $\mathrm{II}$ ).

\section{Discussion}

Quality brood fish is the most important for effective breeding performance (Ingram and Nguyen 2014). Kohinoor (2008) collected native koi (A. testudineus) from natural sources, but there was no detailed information on the origin of broodfish. On the other hand, in the present experiment, the brood fish was collected from the haor area of Netrokona and Sylhet as comparative genetic variation was found better in these two populations in the previous molecular work (Alam et al., unpublished). According to Kohinoor (2008), induced breeding of native koi was conducted from March to July, keeping the Male and female ratio as 1:1, whereas at present, the best- 
induced breeding period was observed from April to June, maintaining the male and female ratio as 1:1 in 500L plastic tank. Sarkar et al. (2005) said that the brood fishes of both males and females were collected from the river Punarbhava, located in Maldah district, West Bengal, from December to February. Chaturvedi et al. (2015) collected mature and healthy brood fish of $A$. testudineus from a private fish farm for breeding research. Samarendra et al. (2016) conducted induced breeding of $A$. testudineus, but no detailed information was found about the brood fish source. In the case of induced breeding of Vietnamese koi, brood fish were collected from Mohalakhsmi Fish Hatchery, Bogra, and another from its own farm's pond (Amin et al., 2015).

The rearing of brood fish has a strong impact on breeding response. In the present experiment, $120-150$ broodfish were stocked in a cemented tank $(5 \times 3 \times 4$ feet) with around 2 feet water height, whereas Kohinoor et al. (1991) reared two hundred brood fish in a $280 \mathrm{~m}^{2}$ earthen rearing pond. Chaturvedi et al. (2015) kept brood fish in a cemented cistern size $(3 \times 2 \times 1 \mathrm{~m})$ with a water depth of 10-12 inches. Sarker et al. (2005) said that the brood fish were maintained in the earthen small-sized pond $(0.05 \mathrm{ha}$, average depth $70-80 \mathrm{~cm})$. Suraiya et al. (2012) broodstocks were reared in rectangular ponds of size $18 \times 14 \mathrm{~m}^{2}$ and an average depth of $1.3 \mathrm{~m}$. Sarkar et al. (2005) conducted captive breeding of $A$. testudineus in separate nylon hapa. Aktar et al. (2014) carried out induced breeding in a cemented tank filled with $30 \mathrm{~cm}$ of water $(10 \mathrm{ft} / 8 \mathrm{ft})$. A $500 \mathrm{~L}$ modified plastic tank was used for ovulation and fertilization, where induced breeding successfully occurred in the present experiment. There is an effect of maturation of the brood on ovulation, fertilization, hatching rate, and also on the survival rate of larvae. Ananda (1973) observed that though many adult females of carp attain the age of maturity, their gonads were still in the immature stage with a lot of fat accumulated in the body cavity. Though the external feature can determine the maturation, the acentric or peripheral location of nuclei is a definite indication of fish readiness for spawning. If the ova nuclei are found to be centrally located, then such a fish would not respond to hormonal breeding treatment (Jhingran and Pullin 1990). Immature eggs fail to get fertilized, and while fertilized, eggs sometimes produce deformed spores that do not hatch out. In the present experiment, since March, weekly checking of the male and female maturity was observed after gentle pressure on the abdomen whereas sperm and egg were come out or not and thus maturity was confirmed.

The administration of the appropriate dose of hormone is the basic to the success of induced breeding; the condition of brood fish and the environmental conditions are also equally important (Pillay 1993). The experiment was carried out at the constant dose of synthetic hormone dose of $0.2 \mathrm{ml} / \mathrm{kg}$ of body weight for females and $0.1 \mathrm{ml} / \mathrm{kg}$ of body weight for males following the information provided by the company. On the other hand, Kohinoor (2008) used the pituitary gland (PG), and the dose was $8-10 \mathrm{mg} / \mathrm{kg}$ for females and $4 \mathrm{mg} / \mathrm{kg}$ for male koi fish. Samarendra et al. (2016) used synthetic hormone WoVA-FH, and the dose was $0.4 \mathrm{ml} / \mathrm{kg}$ for males and $0.9 \mathrm{ml} / \mathrm{kg}$ female. Fecundity is the number of ripening eggs in the female and varied from species, age, length, weight, and environment (Sivashanthini et al., 2008). Fecundity increases with the increase of length, weight, and egg size (Ghafari and Jamili 2010, Lawson, 2011). The early report showed that A. Testudineus, a freshwater fish, had high fecundity (Amornsakun et al., 2005). In this study, the mean fecundity of Sylhet female was 24000-30000 in fish weight range 44-89 g, and the mean fecundity of Netrokona female was 15000-20000 in fish weight range 37-95 g. Sarker et al. (2005) reported that the number of eggs 
released by the female ranged from 52000 to 130000 , indicating high fecundity. Khan and Mukhopadhya (1972) observed fecundity ranging from 10002 to 36477 in the fish size range of 99 to $169 \mathrm{~mm}$. However, Banerjee and Prasad (1974) reported the fecundity of 4588-34993 in the Bihar region in the fish size range 84-100.2 g. Chanchal et al. (1978) reported a minimum of 3481 to a maximum of 42564 in the fish weight range of 9.0-53.1 g. Banerjee and Thakur (1981) reported 2000-13000 eggs in seven sets of induced bred A. testudineus (24.8-40.1 g).

According to Sarkar et al. (2005), the fertilization rates in $A$. testudineus were highest $(98.50 \pm 3.5 \%)$ treated with Wova-FH at female $0.3 \mathrm{ml} / \mathrm{kg}$ and male $0.3 \mathrm{ml} / \mathrm{kg}$ dosage, respectively. In this experiment, the highest fertilization rate was $90.41 \pm 2.10 \%$, and the lowest fertilization rate $84.58 \pm 2.41 \%$. The highest rate of fertilization was occurred by Sylhet $q \times$ Sylhet $\sigma^{\prime}$ and the lowest by Sylhet $q \times$ Netrokona $\sigma^{*}$. Though Sylhet females had the highest fecundity in Sylhet $q \times$ Netrokona o found the lowest fertilization. It might be due to the poor quality of sperm. Therefore, further research on sperm quality may be undertaken. Furthermore, Zalina et al. (2012) reported the highest rate of fertilization $(98.47 \pm 0.45 \%)$ in $A$. testudineus injected LHRHa $2 \mu \mathrm{g} / \mathrm{kg}$ whereas, lower fertilization rates tabulated than the present study as $71.00 \pm 3.97 \%$ and $78.11 \pm 3.24 \%$ in $A$. testudineus injected with $\mathrm{PG}$ at $2 \mathrm{mg} / \mathrm{Kg}$ for male and $7 \mathrm{mg} / \mathrm{Kg}$ for female (Amin et al., 2015). Similarly, Sarker et al. (2005) reported the highest hatching rate, which was $90.50 \pm 3.65$ using Wova-FH at $0.3 \mathrm{ml} / \mathrm{kg}$ for both males and females. Chaturvedi et al. (2015) also reported a hatching rate of $90 \%$ for $A$. testudineus injected with ovatide at $0.6 \mathrm{ml} / \mathrm{kg}$ for females and $0.4 \mathrm{ml} / \mathrm{kg}$ for the male. Zalina et al. (2012) reported the lowest hatching rate of $56.52 \pm 1.35,59.61 \pm 2.18$, and $65.33 \pm 2.69$ in $A$. testudineus injected with different doses of LHRHa. Bhattacharyya and Homechaudhuri (2009) conducted captive breeding of $A$. testudineus with the synthetic hormone Ovaprim with dose as injected 2 $\mathrm{ml} / \mathrm{kg}$ body weight.

In the present experiment, the highest hatching rate was recorded $(77.16 \pm 2.330 \%)$, and the lowest hatching rate was recorded $(42.23 \pm 1.58 \%)$. Sarker et al. (2005) reported the highest hatching rate found $90.5 \pm 3.65$ using Wova-FH at $0.3 \mathrm{ml} / \mathrm{kg}$ for both males and females. Chaturvedi et al. (2015) also reported a hatching rate of $90 \%$ for $A$. testudineus injected with ovatide at $0.6 \mathrm{ml} / \mathrm{kg}$ for females and $0.4 \mathrm{ml} / \mathrm{kg}$ for the male. Zalina et al. (2012) reported the lowest rate of hatching $56.52 \pm 1.35,59.61 \pm 2.18$, and $65.33 \pm 2.69$, respectively, in $A$. testudineus injected with different doses of LHRHa. Bhattacharyya and Homechaudhuri (2009) stated that hatching was $68.57 \%$ in the breeding experiments with Ovaprim. The best survival rate of 14 days old koi ( $A$. testudineus) was recorded in male and female combinations of the Sylhet population, indicating the best broodfish source for induced breeding. However, in most previous reports, there was no data about the survivability of koi fry, and present research might help increase the survivability of koi fry during nursing management in future studies.

Native koi fish (A. testudineus) has a high market price but still could not be brought into commercial culture due to lack of fish seed through induced breeding as well as slow growing pattern. These results showed that the fertilization, hatching, and survival are comparatively higher in $\mathrm{T}_{2}$. The fecundity and egg/gram of body weight are also higher in the Sylhet population rather than the Netrokona population. Finally, these results suggest that the breeding performances of the Sylhet population are better than the Netrokona population. In the present experiment, the breeding of two natural populations of koi fish was compared, and the source of 
quality brood fish was tried to identify, and low-cost breeding techniques were also developed. However, a semi-artificial breeding technique using a 500L plastic tank and further rearing of hatchling in the cemented tank was used, but the survival rate of fish fry was unsatisfactory, which may be due to a lack of live food and a new environment in the plastic tank. Therefore, further monitoring of these issues and continuous domestication with live food in the new environment may reduce the mortality of the native $A$. testudineus in the newly developed incubation system.

Acknowledgement: We acknowledge the financial support from the BSMRAU authority through RMCUGC funded project.

\section{Literature Cited}

Aktar, A., M.J. Sarker and M. Shamsuddin, 2014. Hatchery operation of Thai Koi (Anabas testudineus) in a freshwater fish farm in Bangladesh. Trends Fish. Res., 3(2): 6-10.

Amin, M.R., M.M. Rahman, S. Aktar, M.B. Alam and M.A. Alam, 2015. Induced breeding of Vietnamese koi (Anabas testudineus) using pituitary gland (PG) and ovaprim at Tasty Fish and Feeds Industries Limited, Melandah, Jamalpur. Asian J. Med. Biol. Res., 1(3): 607-611.

Amornsakun, T., W. Sriwatana and P. Promkaew, 2005. Some aspects in early life stage of climbing perch, Anabas testudineus larvae. Songklanakarin J. Sci. Technol., 27: 403-418.

Ananda, J.N., 1973. Experiments on induced breeding of Indian major carps by pituitary hormone injection in Uttar Pradesh. J. Inland Fish. Soc. India, 5: 37-45.

Banerjee, S.R. and D. Prasad, 1974. Observations on reproduction and survival of Anabas testudineus (Bloch) in Bihar region. J. Inland Fish. Soc. India, 6: 6-17.

Banerji, S. R. and N. K. Thakur, 1981. Observations on the spawning behavior of Anabas testudineus (Bloch). Indian J. Anim. Sci., 51: 651-654.

Bhattacharyya, M. and S. Homechaudhuri, 2009. Assessment of captive breeding of Anabas testudineus with the synthetic hormone, ovaprim. Proc. Zool. Soc. India, 62(1): 23-27.

Chanchal, A.K., B.N. Pandey and S. Nath, 1978. Studied on some aspects of the biology of Anabas testudineus (Teleostei: Anabantidae). Matsya, 4: 15-19.

Chaturvedi, C.S., R. Ambulkar, R.K. Singh and A.K. Pandey, 2015. Successful induced spawning of climbing perch, Anabas testudineus (Bloch, 1792), under controlled conditions at Raipur (Chhattisgarh), India. National J. Life Sci., 12(2): 209-214.

Ghafari, S.M. and S. Jamili, 2010. Certain aspects of the reproductive biology of berzem (Barbus pectoralis) in Karoon River. Int. J. Fish. Aquat. Stud., 5: 33-41.

Hafijunnahar, M., A. Rahman and M.M.M. Hossain, 2016. An investigation on breeding biology of Vietnam strain of climbing perch, Anabas testudineus (Bloch) reared in a commercial hatchery. Int. J. Fish. Aquat. Stud., 4(1): 8-12.

Ingram, B.A. and T.T.T. Nguyen, 2014. Broodstock management and breeding in relation to culture-based fisheries. NACA Monograph Series No. 3, 126p.

IUCN, Bangladesh, 2015. Red List of Bangladesh Volume 5: Freshwater Fishes. IUCN, International Union for Conservation of Nature. 378p.

Jhingran, V.G. and R.S.V. Pullin, 1990. A hatchery Manual for the Common Chinese and Indian Major Carp. International Center for Living Aquatic Resources Management. 58p.

Khan, H.A. and S.K. Mukhopadhyay, 1972. On the fecundity of climbing perch, Anabas testudineus (Bloch). J. Inland Fish. Soc. India, 4: 212-213.

Kohinoor, A.H.M. and M. Zaher, 2006. Breeding of exotic koi (Anabas testudineus) at BFRI. Fish. Newslet., 14 (1):1-2. 


\section{BREEDING PERFORMANCES OF A. TESTUDINEUS IN A MODIFIED CONDITION}

Kohinoor, A. H. M., 2008. Seed production of 'koi' and culture management. A Guide Book on Aquaculture Technologies. Bangladesh Fisheries Research Institute and Ministry of Fisheries \& Livestock. The People's Republic of Bangladesh. 96pp.

Kohinoor, A.H.M., M. Akhteruzzaman, M.G. Hussain and M.S. Shah, 1991. Observations on the induced breeding of koi fish, Anabas testudineus (Bloch) in Bangladesh. Bangladesh J. Fish., 14(1-2): 73-77.

Lawson, E.O., 2011. Length-weight relationships and fecundity estimates in mudskipper, Periophthalmus papilio (Bloch and Schneider 1801) caught from the mangrove swamps of Lagos Lagoon, Nigeria. $J$. Fish. Aquat. Sci., 6: 264-271.

Mahmood, S.U., 2003. Effects of Pituitary gland extracts doses on the breeding performance of Koi fish, Anabas testudineus (Bloch 1972). Bangladesh J. Zool., 31(2): 195-201.

Pillay, T.V.R., 1993. Aquaculture: Principles and Practices, 238 Main Street, Cambridge, USA. pp.1561175.

Ponniah, A.G. and U.K. Sarkar, 2000. Evaluation of north east Indian fishes for their potential as cultivable, sport and ornamental fishes along with their conservation and endemic status. Fish Bioder. North East India, 2(229): 11-30.

Samarendra, B., A.S. Ahmed, S. Kumar, R. Gogoi, O. Jomang and S. Baksi, 2016. Courtship behaviour and breeding success of Climbing Perch, Anabas Testudineus (Bloch) in three different breeding sets with the application of a synthetic hormone (WOVA-FH). Int. J. Fish. Aquat. Stud., 6(1): 1-6.

Sarkar, U.K., P.K. Deepak, D. Kapoor, R.S. Negi, S.K. Paul and S. Singh, 2005. Captive breeding of climbing perch Anabas testudineus (Bloch, 1792) with Wova-FH for conservation and aquaculture. Aquac. Res., 36: 941-945.

Shofiquzzoha, A.F.M., M.A., Halim and M.S. Islam, 2018. Growth and production performance of Vietnamese climbing perch (Anabas testudineus) at farm level in Jashore, Bangladesh. Bangladesh $J$. Fish., 30(2): 187-194.

Sivashanthini, K., G.A. Charles and S. Shutharshan, 2008. Fecundity studies of Gerres abbreviates (Blekeer, 1850) from the Jaffna lagoon, Sri Lanka. J. Fish. Aqua. Sci., 3: 320-327.

Suraiya, S., M. Haq and M.M.R. Khan, 2012. Induced breeding and larval rearing of local and Thai Koi (Anabas testudineus, Bloch, 1792). J. Innov. Develop. Strat., 6(1): 63-68.

Talwar, P.K. and A.G. Jhingran, 1991. Inland Fishes of India and Adjacent Countries, Vol. I. Oxford and IBH Publishing, New Delhi, India. 1158p.

Zalina, I., C.R. Saad, A. Christianus and S.A. Harmin, 2012. Induced breeding and embryonic development of climbing perch (Anabas testudineus, Bloch). J. Fish. Aqua. Sci., 7: 291-306.

(Manuscript received: 14 April 2021) 